\title{
Crescimento e produção da mamoneira BRS Paraguaçu sob irrigação, cobertura do solo e adubação orgânica
}

\author{
Nubia M. Ferreira ${ }^{1}$, Evandro F. de Mesquita ${ }^{2}$, Francisco V. da S. Sá3, \\ Antonio M. P. Bertino ${ }^{1}$, Emanoela P. de Paiva ${ }^{4} \&$ Soahd A. R. Farias ${ }^{5}$ \\ ${ }^{1}$ Programa de Pós-Gradiação em Agrônomia/Universidade Federal da Paraíba. Areia, PB. E-mail: nubiamarisa1@hotmail.com; ampbantonio@gmail.com \\ ${ }^{2}$ Universidade Estadual da Paraíba. Catolé do Rocha, PB. E-mail: elmesquita4@uepb.edu.br \\ ${ }^{3}$ Programa de Pós-Graduação em Manejo de Solo e Água/Universidade Federal Rural do Semi-Árido. Mossoró, RN. E-mail: vanies_agronomia@hotmail.com \\ (Autor correspondente) \\ ${ }^{4}$ Programa de Pós-Graduação em Fitotecnia/Universidade Federal Rural do Semi-Árido. Mossoró, RN. E-mail: emanuelappaiva@hotmail.com \\ ${ }^{5}$ Unidade Acadêmica de Engenharia Agrícola/Universidade Federal de Campina Grande. Campina Grande, PB. E-mail: soahd.rached@gmail.com
}

\section{Palavras-chave:}

Ricinus communis L.

sistema de cultivo

manejo de água

\section{R E S U M O}

Objetivou-se, neste trabalho, avaliar o crescimento e produção da mamona cv. BRS-188 Paraguaçu que tem sido recomendada para a região Nordeste do Brasil em relação à adubação orgânica, cobertura morta e níveis de reposição de água. Para isto foi desenvolvido o experimento em condições de campo, na cidade de Catolé do Rocha, PB, usando-se um delineamento experimental em blocos casualizados com fatorial $2 \times 2 \times 4$, constituído de dois níveis de reposição de água em função da evapotranspiração da cultura - ETc de 100 e 50\% no solo sem e com cobertura morta (Cenchrus ciliares L) e quatro níveis de biofertilizante bovino $\left(0 ; 1,2 ; 2,4\right.$ e 3,6 L planta $\left.^{-1}\right)$, aplicados ao solo totalizando 16 tratamentos com três repetições e dez plantas por tratamento totalizando 48 parcelas experimentais. As plantas irrigadas com $50 \%$ da ETc, no solo com cobertura morta e biofertilizante bovino na dose de 3,6 L planta ${ }^{-1}$ atingiram áreas foliares e produções semelhantes às plantas cultivadas em sistema convencional sem cobertura e irrigadas com $100 \%$ da ETc.

\section{Key words:}

Ricinus communis L. cropping system water management

\section{Growth and production of castor bean BRS Paraguaçu under irrigation, soil mulching and organic fertilization}

\begin{abstract}
A B S T R A C T
The objective of this study was to evaluate the growth and production of castor bean BRS188 Paraguaçu, which has been recommended for the Northeast of Brazil in relation to organic fertilization, mulching and levels of water replacement. For this, an experiment was conducted under field conditions in the municipality of Catole of Rocha-PB, using a randomized complete block design with factorial $2 \times 2 \times 4$, consisting of two levels of replacement of water through irrigation due to the crop evapotranspiration - ETc 100 and $50 \%$, with and without mulch (Cenchrus ciliares $\mathrm{L}$ ) and four levels of bovine biofertilizer ( 0 , 1.2, 2.4 and 3.6 L plant ${ }^{-1}$ ), applied to the soil, totaling 16 treatments with three replications and ten plants per treatment totaling 48 experimental plots. Plants irrigated with $50 \%$ of ETc, under mulch and bovine fertilizer at a dose of $3.6 \mathrm{~L} \mathrm{plant}^{-1}$ reached leaf area and similar productions to plants grown in conventional system without mulch cover and irrigated with $100 \%$ ETc.
\end{abstract}




\section{INTRODUÇÃo}

A mamoneira (Ricinus communis L.) é base dos mais diversos produtos industriais como, a exemplo da extração do óleo e a produção de torta que é usada como fertilizante e condicionante do solo. Além disto, com a desintoxicação a torta pode ser usada como fonte proteica para suplementação da dieta de rebanho bovino (Mesquita et al., 2012). Por ser uma das culturas eleitas pelo Programa Federal de biodiesel para fornecer matéria-prima para a produção de um biocombustível apontado como renovável e menos poluente que o seu concorrente fóssil, o óleo diesel (Severino et al., 2006). Neste contexto a cultura é amplamente difundida em quase todas as regiões do Brasil, por suas características xerófilas e heliófilas o que lhe garante viabilidade de adaptação e produção (Nobre et al., 2012).

Apesar da sua adaptabilidade, para o desenvolvimento adequado visando produções satisfatórias, torna-se necessário suplemento hídrico suficiente nas respectivas fases fenológicas, o que requer estudos sob o manejo da irrigação e qualidade água da irrigação para a cultura (Freitas et al., 2010; Souza et al., 2010; Formiga, 2011; Ribeiro et al., 2012). Isto indica a primazia de estudos que viabilizem o manejo da irrigação da cultura principalmente no semiárido brasileiro onde se caracterizam as limitações hídricas em termos de pluviosidade, distribuição das chuvas e qualidade das águas, quanto à salinidade para irrigação (Nobre et al., 2012; Ribeiro et al., 2012). Outra estratégia pode ser a cobertura morta como meta para redução das perdas de água do solo favorecendo também o desempenho das culturas (Souza et al., 2008; Sousa \& Guerra, 2012).

O monitoramento do requerimento de água e do estresse hídrico de culturas é importante para programar a irrigação e implica em parâmetros ligados à eficiência da adubação para que as plantas possam obter máxima produtividade. Grande parte dos solos da região semiárida brasileira, área de principal foco do cultivo da mamoneira no Brasil, além de apresentar problemas relacionados à baixa disponibilidade de água, é caracterizada pela baixa disponibilidade de nitrogênio e fósforo enquanto a correção desta insuficiência se faz, normalmente, através de aplicações de elevados níveis de fertilizantes minerais (Menezes \& Oliveira, 2008) uma solução insatisfatória do ponto de vista econômico e ambiental.

Araújo et al. (2009), Diniz Neto et al. (2009), Dantas et al. (2011) e Mesquita et al. (2012) constataram demanda elevada da mamoneira por nitrogênio durante a fase vegetativa; desta forma apresenta, quando cultivada com deficiência do referido macronutriente, inibição no crescimento inicial; existem, atualmente, várias fontes de adubos orgânicos ricos em nitrogênio utilizadas na agricultura mas o esterco bovino é o que exibe o maior potencial de uso como fertilizante na sua forma sólida e líquida, sobretudo em pequenos estabelecimentos agrícolas na região Nordeste do Brasil porém pouco se conhece a respeito das dosagens a serem utilizadas na cultura da mamona em clima semiárido que permitam a obtenção de rendimentos com viabilidade técnica e econômica.

Com o exposto, tornou-se necessário estudar os níveis adequados de adubação orgânica e a reposição de água nos solos de maior ocorrência na região semiárida (Neossolo) que contribuam para sustentabilidade de novas áreas com a cultura da mamoneira para melhoria de renda da propriedade tentativa de inserção da região semiárida no Programa Federal de produção de biodiesel; objetivou-se, então, avaliar o crescimento e produção de plantas de mamoneira cv BRS188 Paraguaçu em função de lâminas de irrigação e níveis de biofertilizante bovino como adubação orgânica no solo com e sem cobertura morta.

\section{Material e Métodos}

O experimento foi desenvolvido no período de junho a dezembro de 2012 com a cultivar de mamoneira BRS 188 Paraguaçu em condições de campo, no Campus-IV/ Universidade Estadual da Paraíba - UEPB, numa área total de $600 \mathrm{~m}^{2}$, pertencente ao Departamento de Agrárias e Exatas, localizado pelas coordenadas geográficas $\left(6^{\circ} 2^{\prime} 38^{\prime \prime} \mathrm{S} ; 37^{\circ} 44^{\prime}\right.$ $48^{\prime \prime} \mathrm{W}$ ) e altitude de $274 \mathrm{~m}$. O clima do município, de acordo com a classificação de koppen, é do tipo BSWh ', que significa quente e seco, do tipo estepe, com temperatura média mensal superior a $18{ }^{\circ} \mathrm{C}$ e o solo, de acordo com o Sistema Brasileiro de Classificação de Solos, é denominado Neossolo Flúvico (EMBRAPA, 2013) (Tabela 1).

Os tratamentos foram: dois níveis de reposição de água de irrigação equivalentes a 100 e $50 \%$ da evapotranspiração da cultura - ETc; no solo sem e com cobertura morta e quatro níveis de biofertilizante bovino $\left(0,0 ; 1,2 ; 2,4\right.$ e 3,6 $\left.\mathrm{L}_{\text {planta }}{ }^{-1}\right)$, utilizados como adubação orgânica, com frequência de aplicação mensal.

O delineamento experimental foi em blocos casualizados, no esquema fatorial $2 \times 2 \times 4$, constituído por níveis de reposição de água do solo em função da evapotranspiração da cultura - Etc, no solo sem e com da cobertura morta na superfície do solo e quatro níveis de biofertilizante bovino. A combinação entre os fatores lâminas de água (LA), cobertura (C) e biofertilizante bovino (BB) resultou em 16 tratamentos dispostos em três blocos; assim, o experimento totalizou 48 parcelas; em cada parcela experimental constituída por uma área útil de $12 \mathrm{~m}^{2}$, foram cultivadas 3 plantas totalizando 144 plantas, espaçadas a $2 \times 2 \mathrm{~m}$, correspondente a 0,06 ha.

A irrigação das plantas foi realizada pelo método de irrigação localizada por gotejamento, de acordo com a

Tabela 1. Características químicas do solo quanto à fertilidade e do adubo orgânico líquido (biofertilizante líquido) à base de esterco bovino, aos 60 dias após o inicio da fermentação anaeróbica

\begin{tabular}{|c|c|c|c|c|c|c|c|c|c|c|c|c|c|c|c|}
\hline \multicolumn{11}{|c|}{ Solo } & \multicolumn{5}{|c|}{ Biofertilizante } \\
\hline${ }^{*} \mathrm{CE}$ & $\mathrm{pH}$ & $\mathbf{P}$ & $\mathrm{K}^{+}$ & $\mathrm{Ca}^{+2}$ & $\mathrm{Mg}^{+2}$ & $\mathrm{Na}^{+} \mathrm{Al}^{3+}$ & $\mathrm{H}^{+}+\mathrm{Al}^{3+}$ & SB & $T$ & MO & CE & $\mathrm{Ca}^{2+} \mathrm{Mg}^{2+} \mathrm{Na}^{+}$ & $\mathrm{K}^{+}$ & $\mathrm{CO}_{3}{ }^{2-} \mathrm{HCO}_{3}-\mathrm{SO}_{4}{ }^{2-}$ & $\mathbf{P}$ \\
\hline $\mathrm{dS} \mathrm{m}^{-1}$ & $\mathrm{CaCl}_{2}$ & $\mathrm{mg} \mathrm{dm}^{-3}$ & & & & $\mathrm{cmol}_{\mathrm{c}} \mathrm{dm}$ & & & & $\mathrm{g} \mathrm{kg}^{-3}$ & dS $\mathrm{m}^{-1}$ & & $\mathrm{cmol}_{\mathrm{c}} \mathrm{L}^{-1}$ & & $\left.(\mathrm{mg} \mathrm{dm})^{3}\right)$ \\
\hline 0,06 & 6,55 & 11 & 0,51 & 3,55 & 3,15 & $0,290,00$ & 0,66 & 7,21 & 7,87 & 9,0 & 8,08 & $\begin{array}{lll}2,71 & 2,04 & 2,07\end{array}$ & $1,69 \quad 4,95$ & $\begin{array}{lll}0,43 & 2,03 & 1,20\end{array}$ & 56,00 \\
\hline
\end{tabular}


evapotranspiração da Cultura-ETc utilizando o tanque Classe A para a estimativa da evapotranspiração de referência ETo $\left(\mathrm{mm} \mathrm{d}^{-1}\right)$ sendo corrigida pelo Kc da cultura de acordo com o estágio de desenvolvimento da planta, obtendo o uso consuntivo $\left(\mathrm{Uc}_{\mathrm{c}}\right.$ ) considerando o percentual de área molhada $(\mathrm{P})=40 \%$, portanto, para fins do calculo da lâmina de irrigação líquida diária $(\mathrm{LLD}=\mathrm{ETc})$, tem-se $\mathrm{LLD}=\mathrm{Uc}$ $\mathrm{x} \mathrm{P} / 100\left(\mathrm{~mm} \mathrm{~d}^{-1}\right)$; a partir deste valor, determinou-se as lâminas aplicadas correspondentes a 100 e 50\% LLD que eram aplicadas diariamente e se usava o tempo de aplicação como forma de redução do volume de água $\left(\mathrm{CE}_{\text {água }}=0,8 \mathrm{dS} \mathrm{m}^{-1}\right)$, isto é, o tempo era reduzido pela metade do que era oferecido ao tratamento 1 . As variáveis atribuídas no experimento foram: coeficiente do tanque classe $\mathrm{A}(\mathrm{Kp})=0,75$; coeficiente de cultivo variável de acordo com o estágio da cultura $(\mathrm{Kc})=$ fase inicial 0,40 ; vegetativa/desenvolvimento $=0,80$; floração $=1,20$; formação da colheita $=0,80$ e maturação $=0,40$. A vazão do gotejador $(q)=7,8 \mathrm{~L} \mathrm{~h}^{-1}$ foi obtida através de teste em campo com os emissores instalados no espaçamento 2,0 $\mathrm{m}$ entre mangueiras com gotejadores a cada 2,0 $\mathrm{m}$ na linha, isto é, resultando em uma área $(\mathrm{AS})=4,0 \mathrm{~m}^{2}$ por emissor.

A diferenciação das lâminas foi feita aos 21 dias após a semeadura (DAS) tal como a colocação da cobertura morta na superfície do solo na espessura de $5 \mathrm{~cm}$ na projeção da copa $(40 \mathrm{x} 40 \mathrm{~cm})$ utilizando-se, como material, capim buffel (Cenchrus ciliares L) seguindo os padrões descritos por Marenco-Caetano et al. (2012).

$\mathrm{O}$ biofertilizante à base de esterco bovino e enriquecido com leguminosa, foi produzido de forma anaeróbica em biodigestor plástico com capacidade para $240 \mathrm{~L}$, contendo uma mangueira ligada a recipiente plástico transparente com água, para retirada do gás metano produzido durante a fermentação pelas bactérias anaeróbias. O material utilizado para a produção do referido fertilizante constou de $70 \mathrm{~kg}$ de esterco verde de vacas em lactação e de $120 \mathrm{~L}$ de água, além de $5 \mathrm{~kg}$ de açúcar e $5 \mathrm{~L}$ de leite para aceleração do metabolismo das bactérias mais $5 \mathrm{~kg}$ de matéria verde de leguminosa (Vigna unguiculata (L.) Walp.). Após 60 dias de incubação do biofertilizante foi coletada uma amostra do mesmo, para caracterização química em laboratório com base nos padrões de análise de água (Tabela 1).

A semeadura foi feita em covas com profundidade de 3 $\mathrm{cm}$ colocando-se 6 (seis) sementes da mamoneira cv. BRS 188- Paraguaçu por cova; aos 10 DAS foi realizado o primeiro desbaste deixando-se as três plantas mais vigorosas por cova e um segundo desbaste, aos 21 DAS, deixando-se apenas as plantas mais vigorosas. Quinzenalmente foi feito, ao longo do experimento, o monitoramento manejo fitossanitário a fim de evitar problemas com pragas ou doenças.

Aos 180 (DAS) foram avaliados a altura da planta medida do colo até o ápice, o diâmetro do caule com a leitura efetuada a $2 \mathrm{~cm}$ da região do colo de cada planta com paquímetro digital, a área foliar foi mensurada a partir de folhas com comprimento mínimo de 3,0 cm. O cálculo da área foliar (AF) foi feito de acordo com o método de Wendt (1967), cuja fórmula utilizada foi $\log (\mathrm{Y})=-0,346+[2,152 * \log (\mathrm{X})]$. Onde: $\mathrm{Y}=$ área foliar $\left(\mathrm{cm}^{2}\right)$ e $\mathrm{X}=$ comprimento da nervura central da folha $(\mathrm{cm})$.

Na mesma idade (180 DAS) os frutos, até o último cacho maduro antes do corte, foram contados e obtida a massa das sementes de cada tratamento. A produção da cultura foi representada pelo número de cachos, número de frutos por racemo, número de sementes por racemo, massa de sementes por planta, massa de 100 sementes e produtividade e teor de óleo .

Os dados obtidos foram submetidos à análise de variância e comparação de médias qualitativas pelo teste $\mathrm{F}$ e análise de regressão referente aos níveis do adubo orgânico utilizando o software SISVAR (Ferreira, 2011).

\section{Resultados e Discussão}

A redução de 100 para $50 \%$ das lâminas de irrigação promoveu um declínio de 104,28 para $93,97 \mathrm{~cm}$, resultando numa inibição de $9,88 \%$ no crescimento das plantas em altura (Figura 1 A). De acordo com Taiz \& Zaiger (2013), os processos fisiológicos são afetados pelo estresse hídrico haja vista que em condição de menor disponibilidade de água as plantas mantêm suas células das zonas de crescimento em condições de flacidez reduzindo o coeficiente da divisão celular e a expansão das células prejudicando o crescimento das plantas. Apesar da inibição do crescimento das plantas com redução da disponibilidade de água, os resultados superam os 45,9 e os $81,9 \mathrm{~cm}$ apresentados por Souza et al. (2010) e Ribeiro et al. (2012) aplicação de esgoto doméstico em plantas das cultivares BRS Energia e BRS 149 Nordestina irrigadas com água de esgoto doméstico, com suplementação mineral; entretanto, os resultados divergiram dos obtidos por Dantas et al. (2011) os quais detectaram diferenças significativas dos níveis de biofertilizante bovino no crescimento em altura da mamoneira EBDA MPB1 nos $1^{\circ} \mathrm{e}$ $2^{\circ}$ ciclos de cultivo a diferença pode ser função das menores exigências nutricionais da BRS-188 Paraguaçu utilizada no experimento.

Observa-se resposta quadrática significativa em função dos níveis de biofertilizante bovino aplicado ao solo no diâmetro caulinar obtendo-se $57,73 \mathrm{~mm}$ correspondente à dose estimada 3,6 $\mathrm{L}_{\text {planta }}{ }^{-1}$, quando as plantas foram irrigadas com a lâmina de $100 \%$ da evapotranspiração da cultura (ETc) com base na evaporação do tanque de classe A (Figura 1B).

Para as plantas conduzidas sob estresse hídrico (50\% da ETc), os dados do diâmetro caulinar não se ajustaram a nenhum modelo matemático com médias $32,30 \mathrm{~mm}$ cujas plantas irrigadas com $100 \%$ da ETc proporcionaram incrementos $44,22 \%$ em comparação às plantas submetidas ao estresse hídrico ( $50 \%$ da ETc) evidenciando que em condições de clima semiárido a cultura da mamoneira necessita do suplemento da irrigação durante o período de estiagem para obter maiores crescimentos (Figura 1B) resultados esses superiores os $(39,06$ $\mathrm{mm}$ ) aos observados na cultivar Mirante 10 por Diniz Neto et al. (2009), indicando a importância do suprimento hídrico e nutricional para a cultura da mamoneira resultado semelhante ao observado neste trabalho para as plantas cultivadas na lâmina de $50 \%$ da ETc.

Observa-se, na Figura 1C e 1D, que houve resposta quadrática significativa $(\mathrm{P}<0,01)$ dos níveis de biofertilizante bovino aplicado ao solo com e sem stress hídrico (100\% da ETc) na presença da cobertura morta na superfície do solo, para a 
A.

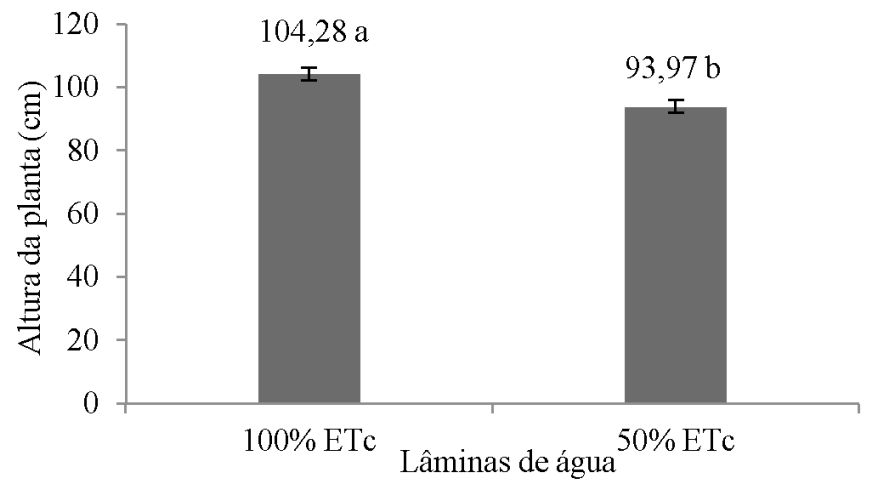

C.

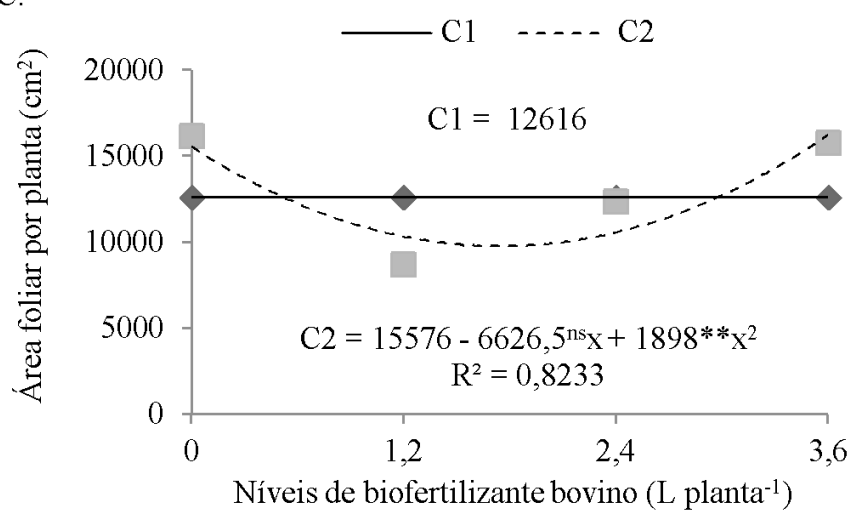

B.

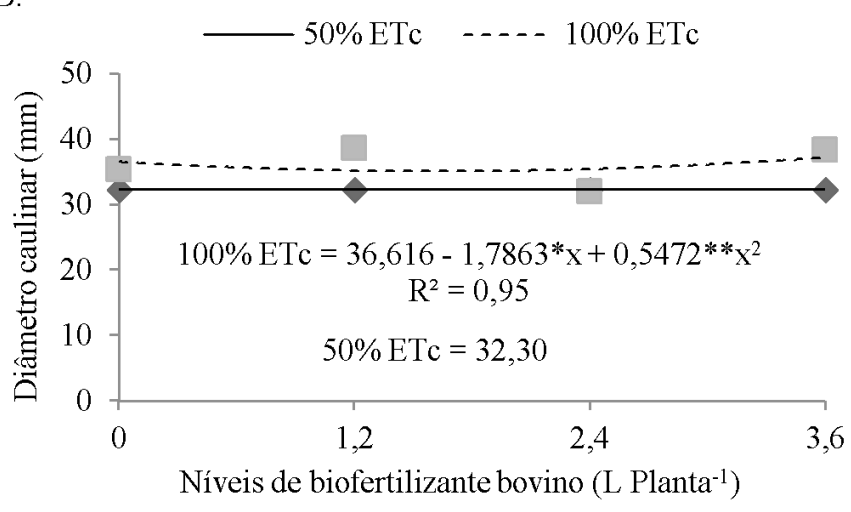

D.

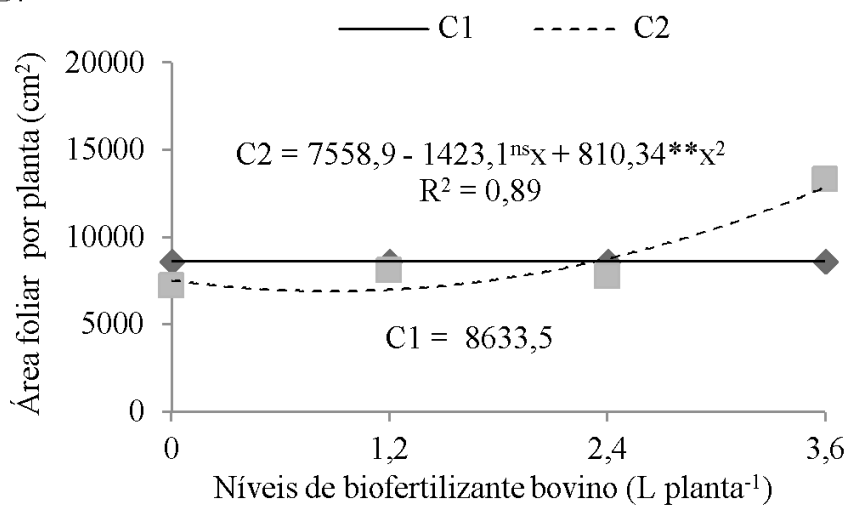

Médias seguidas de mesma letra não diferem entre si pelo teste de ' $T$ ' a 0,05 de probabilidade

Figura 1. Altura (A), diâmetro caulinar (B) e Área foliar (C e D) da mamoneira BRS 188- Paraguaçu em função de níveis de biofertilizante bovino, das lâminas de $100 \%$ (C) e 50\% ETc (D), no solo sem (-) e com (- - -) cobertura morta

área foliar das plantas, avaliada aos $180 \mathrm{DAS}$, obtendo-se valores máximos de $\left(12.937,74\right.$ e $\left.27.131,34 \mathrm{~cm}^{2}\right)$, obtida com a dose de $3,6 \mathrm{~L}_{\text {planta }}{ }^{-1}$. Nos tratamentos referentes às plantas formadas com $50 \%$ ETc na ausência da cobertura morta sobre a superfície do solo, os valores da área foliar por planta não se ajustaram a nenhum modelo matemático $\left(8.633,5\right.$ e $\left.12.616 \mathrm{~cm}^{2}\right)$.

Verificou-se que a quantidade de água aplicada referente a $100 \%$ da evapotranspiração da cultura- ETc foi determinante para aumentar significativamente a área foliar da mamoneira evidenciando a importância do manejo da irrigação em condições de clima semiárido. Os dados obtidos foram inferiores aos $45.475 \mathrm{~cm}^{2}$, computados por Formiga (2011) para a condição sem estresse hídrico (100\% da ETc), aos 180 DAS com cultivar BRS Nordestina; os resultados observados na

A.

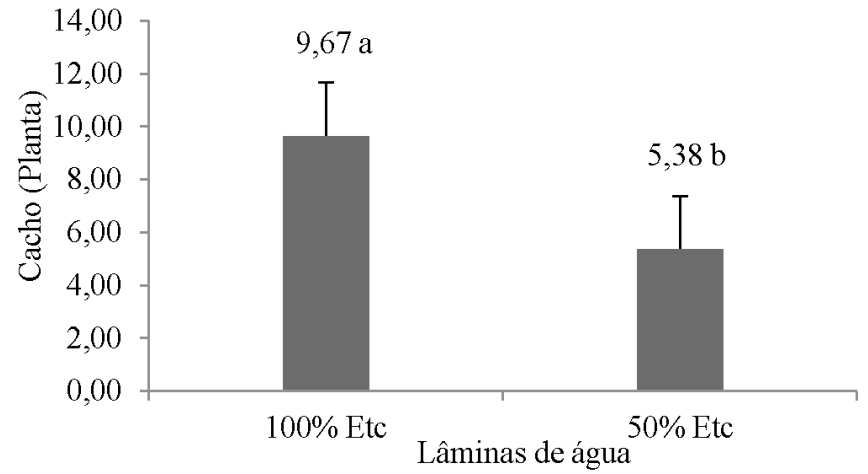

pesquisa estão em coerência com os observados por Mesquita et al. (2012) para a mamoneira BRS Paraguaçu.

O aumento do número de cachos por planta de 5,38 para 9,67 expressa uma superioridade de 44,36\% das plantas formadas sem estresse hídrico em comparação às plantas cultivadas com déficit hídrico (Figura 2A). Esses aumentos são respostas dos efeitos positivos do solo irrigado com $100 \%$ da ETc, tornando o solo mais úmido e menos aquecido resultando maior eficiência do uso da água e, em contrapartida, ganhos de produção. Esses resultados se assemelham às constatações de Freitas et al. (2010) de que 0 acréscimo das lâminas de irrigação proporcionou aumento expressivo do número de cachos da mamoneira EBDA MPB1.

Os resultados obtidos na lâmina de $100 \%$ da ETc, superaram os 7,35 cachos obtidos por Nobre et al. (2012), com a aplicação

B.

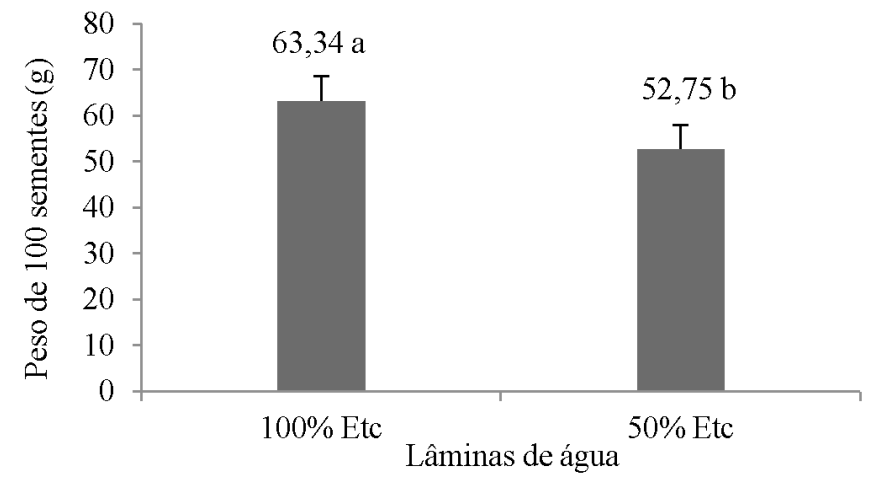

Médias seguidas de mesma letra não diferem entre si pelo teste de ' $T$ ' a 0,05 de probabilidade

Figura 2. Número de cachos por planta (A) e massa de 100 sementes de mamoneira BRS 188- Paraguaçu, em função das lâminas de irrigação 
de $150 \%$ da dose recomendada de nitrogênio para ensaios em vasos $\left(100 \mathrm{mg}_{\text {vaso }}{ }^{-1}\right)$ na cultivar BRS Energia. Tais resultados demostram a importância da disponibilidade hídrica na cultura da mamoneira.

Apesar da interação níveis de biofertilizante $\mathrm{x}$ lâminas de água $\mathrm{x}$ cobertura morta não exercer efeitos significativos sobre a massa de 100 sementes (Figura 2B), esta variável respondeu à ação isolada das lâminas de irrigação. Pelos resultados da Figura 2B percebe-se, ao relacionar os valores de 52,75 com 63,34 g referentes aos tratamentos 50 e $100 \%$ da ETc, que o aumento da disponibilidade de água promoveu um incremento de $16,75 \%$ no peso de 100 sementes cujos resultados obtidos corroboram com Freitas et al. (2010) ao constatar aumento da massa de cem sementes com o uso da irrigação.

Para a lâmina de irrigação de $50 \%$ da ETc e o sistema de cultivo sem cobertura morta, o número de frutos por racemo não se ajustou a nenhum modelo matemático com média de 41,58 . O número de frutos por racemo irrigadas com $50 \%$

A.

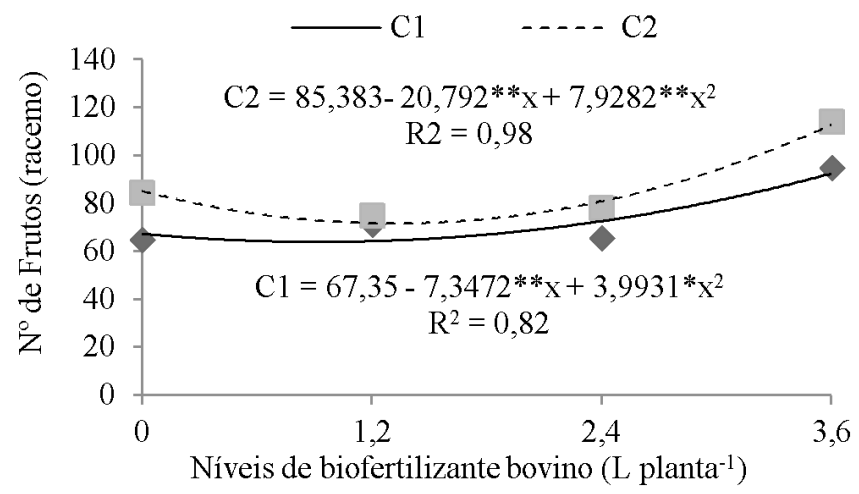

C.

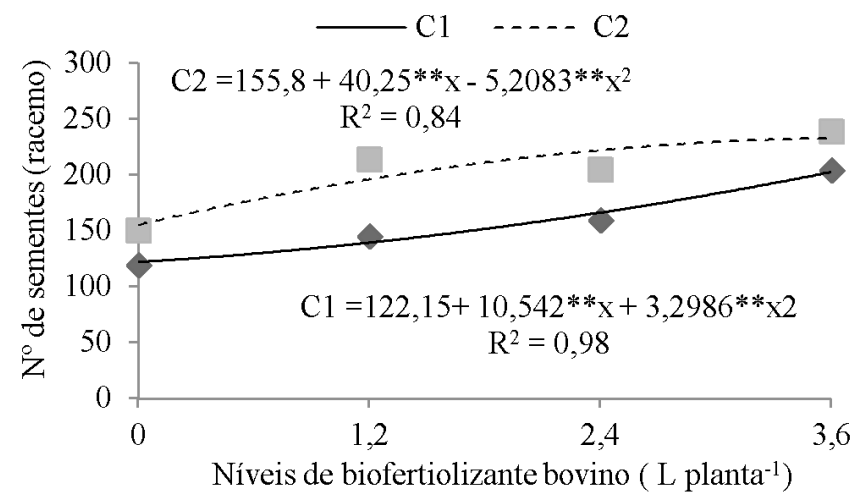

E.

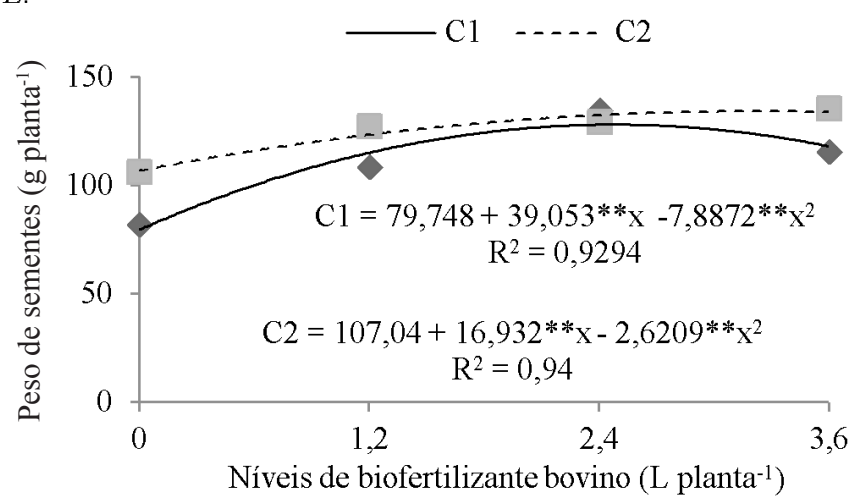

da ETc associado ao sistema de cobertura morta aumentou com acréscimo da dose de biofertilizante bovino aplicado ao solo, sendo maior o valor de 93 frutos correspondente à dose estimada de 3,6 $\mathrm{L}_{\text {planta }}{ }^{-1}$ (Figura 3B). A prática da cobertura morta é muito importante para regiões de clima árido $\mathrm{e}$ semiárido, assim como observado na cidade Catolé do Rocha, inserida no alto sertão paraibano, com taxa de evaporação de água do solo de até $12 \mathrm{~mm}$ dia no período de estiagem; assim, esta prática tem o intuito de manter o solo úmido por mais tempo favorecendo o desenvolvimento da cultura, fato confirmado por Silva et al. (2011) com a cultura do milho em que o sistema com cobertura morta proporcionou incrementos de 13,9\% na produção da matéria seca com grãos de milho em comparação ao solo desnudo.

Para a lâmina de $100 \%$ da ETc e os sistemas de cultivo sem e com cobertura morta na superfície do solo, os valores dos números de frutos por planta apresentaram uma variação polinomial crescente com valores máximos de 92,56 e 113,28

B.

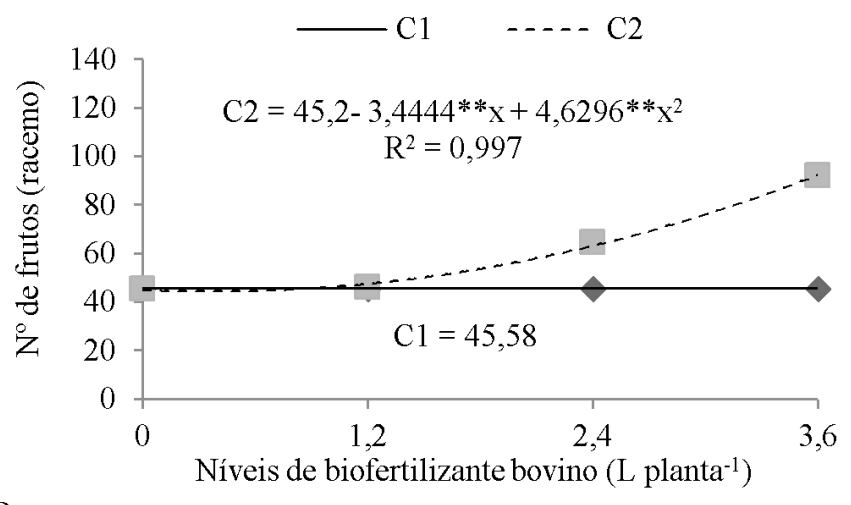

D.

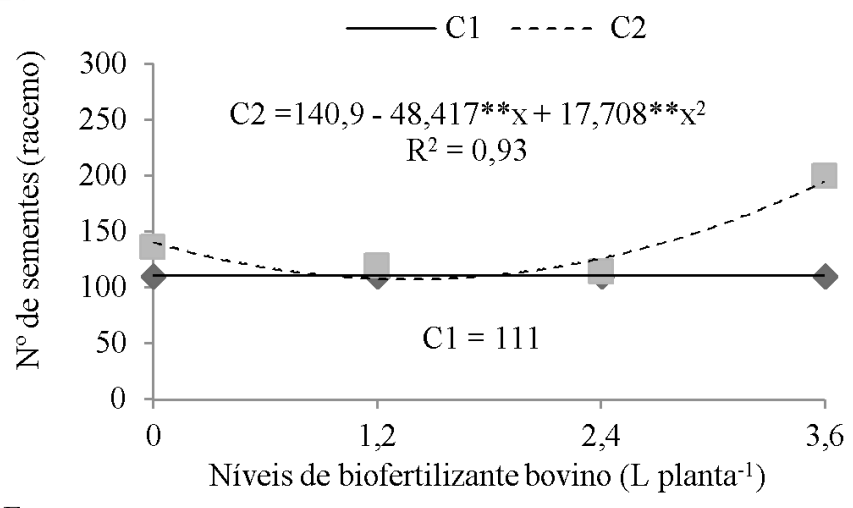

F.

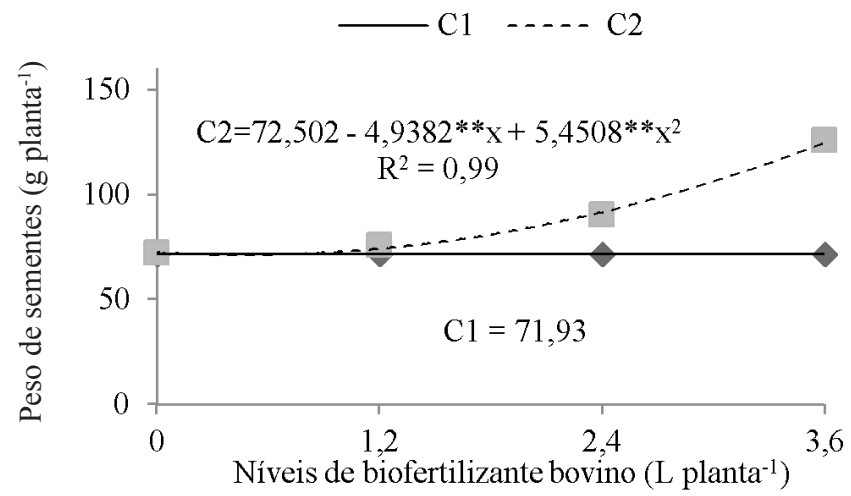

Figura 3. Número de frutos por racemo (A e B), Número de sementes por racemo (C e D), Peso de sementes por planta (E e F) da mamoneira BRS 188- Paraguaçu em função de níveis de biofertilizante bovino, das lâminas de 100\% (A, C e E) e $50 \%$ da ETc (B, D e F), no solo com (- - -) e sem (-) cobertura morta 
referentes à dose de 3,6 $\mathrm{L}_{\text {planta }}{ }^{-1}$, respectivamente (Figura 3A). Alguns estudos já relataram que o biofertilizante é um efluente líquido que pode alterar beneficamente as propriedades físicas, químicas e biológicas do solo, além de melhorar a capacidade de retenção de água por ser uma matéria orgânica (Nascimento, 2010), favorecendo a maior disponibilidade de água e nutrientes para as plantas de mamoneira tal como verificado pelos resultados deste trabalho, superiores aos observados por Silva et al. (2008) de 40 frutos por planta de mamoneira BSR Paraguaçu cultivadas sob salinidade de $0,7 \mathrm{ds} \mathrm{m}^{-1}$.

Nos tratamentos irrigados com $100 \%$ da ETc os maiores números de sementes por planta foram de 200 e 233 na ausência e na presença da cobertura morta, respectivamente, alcançados com a dose de 3,6 $\mathrm{L}_{\text {planta }^{-1}}$ (Figura 3C). Os tratamentos na presença de cobertura morta superaram na ordem 44,5 e $15,87 \%$ os tratamentos na ausência da cobertura morta, ambos irrigados com 100 e $50 \%$ da ETC, respectivamente. Resposta semelhante foi obtida por Freitas et al. (2010) devido à maior disponibilidade hídrica do solo.

O número de cachos, de frutos e das sementes da cultura, decresceu com a diminuição do teor de água de 100 para $50 \%$ da ETc na ausência da cobertura morta reduzindo significativamente essas variáveis; entretanto, o uso da cobertura morta proporcionou resultados favoráveis possivelmente pela manutenção da umidade do solo.

Com referência ao número de sementes por racemo submetido a $50 \%$ da ETc na ausência da cobertura morta no desdobramento da interação tripla, os dados não se ajustaram ao nenhum modelo matemático com incremento dos níveis de biofertilizante, com média de 111 ; já na presença da cobertura

A.

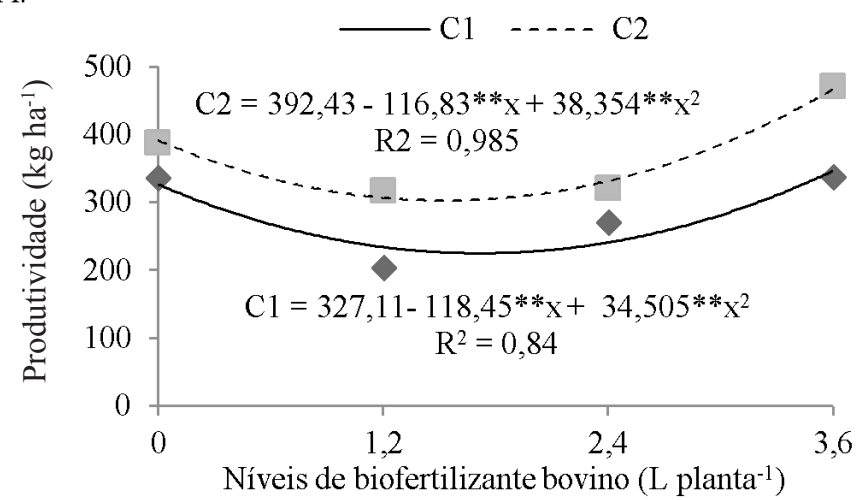

C.

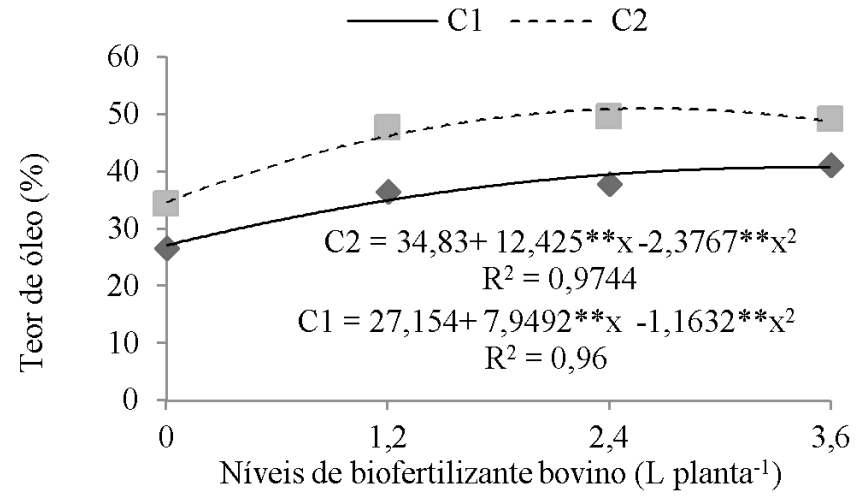

morta o máximo do número de sementes $\left(\right.$ Planta $\left.^{-1}\right)$ foi de 196 referente à dose estimada de 3,6 L planta $^{-1}$ (Figura 3D), o correspondendo a um incremento de $61 \%$ em comparação aos tratamentos com cobertura morta em relação à sua ausência, evidenciado o benefício da cobertura morta em condições de clima semiárido haja vista que resultados observados superam os obtidos por Ribeiro et al. (2012) (181 sementes) no genótipo de mamoneira EBDA MPB01 sob irrigação com diferentes diluições de esgoto domestico tratado.

A massa de sementes por plantas irrigadas com 100\% ETc para os tratamentos sem e com cobertura morta na superfície do solo utilizando-se as equações quadráticas (Figura $3 \mathrm{E}$ ) foi de 128 e 134, correspondendo aos níveis de 2,4 e 3,6 L planta ${ }^{-1}$, respectivamente. Comparativamente houve um incremento de $4,48 \%$ entre os sistemas com e sem cobertura morta. Tais resultados foram superiores aos observados por Silva et al. (2008) que obtiveram peso médio de $75 \mathrm{~g}$ de sementes por planta.

É provável que a cobertura morta do solo tenha diminuído a evapotranspiração mantendo o solo mais úmido, fato de grande importância para a região semiárida que apresenta alta temperatura do ar e do solo. A superioridade no número de sementes das plantas formadas sem estresse hídrico pode estar relacionada ao fato de que, se a deficiência hídrica ocorre durante o desenvolvimento do pólen, a meiose apresenta anomalias cromossômicas e surgem distúrbios, especialmente na metáfase e na anáfase; desta forma, o estresse hídrico diminui a fertilidade de pólen que, por sua vez, está diretamente ligado à quantidade de sementes por planta (Larcher, 2006).

Analisando a lâmina de $50 \%$ da ETc, as maiores massas de sementes por planta foram observadas no plantio com

B.

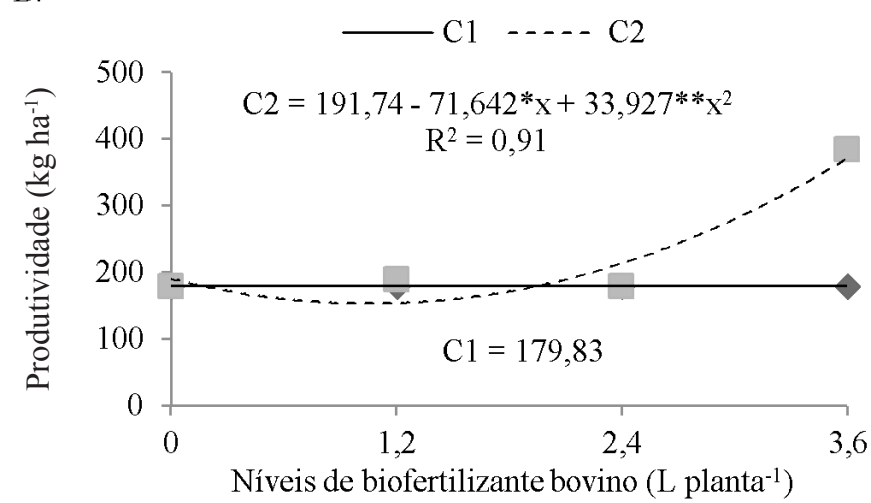

D.

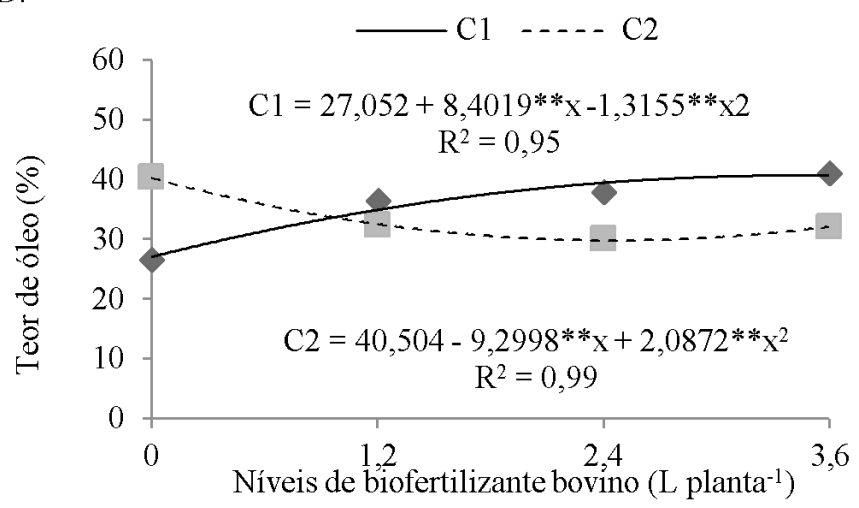

Figura 4. Produtividade (A e B) e o Teor de óleo de sementes (C e D) de mamoneira BRS 188- Paraguaçu em função de níveis de biofertilizante bovino, das lâminas de 100\% (A e C) e 50\% da ETc (B e D), no solo com (- - -) e sem (-) cobertura morta 
cobertura morta na dose de 3,6 $\mathrm{L}_{\text {planta }}{ }^{-1}$, sendo o valor médio de 125,36 g. Para o cultivo sem cobertura morta o número de sementes por racemo não se ajustou a nenhum modelo matemático com acréscimo dos níveis de biofertilizante bovino com média de 71,93 g (Figura 3F). Comparativamente, observa-se uma superioridade no número de sementes de $42,62 \%$ no sistema com cobertura morta em comparação ao sistema sem cobertura morta demonstrando a importância desta prática para região de clima semiárido com baixo índice pluviométrico associado à irregularidade das chuvas, além da alta taxa de evaporação.

O potencial produtivo obtido nas plantas irrigadas com $50 \%$ da ETc, foi de 179,83 e $347,87 \mathrm{~kg} \mathrm{ha}^{-1}$ para os sistemas sem e com cobertura morta, respectivamente (Figura 4B). As maiores produtividades alcançadas foram de 373,52 e 468,90 $\mathrm{kg} \mathrm{ha}^{-1}$, obtidas nos tratamentos irrigados com $100 \%$ da ETc no sistema de cultivo com cobertura, respectivamente (Figura $4 \mathrm{~A}$ ), evidenciando uma superioridade $20,2 \%$ no sistema com cobertura morta em comparação ao sistema sem cobertura morta. A produtividade foi afetada negativamente nas plantas submetidas ao estresse hídrico evidenciando que, a para obter produções satisfatórias em clima semiárido, a mamoneira necessita de suplementação hídrica.

Quanto ao teor de óleo nas sementes, observam-se respostas quadráticas do acúmulo de óleo das sementes conforme as aplicações dos níveis de biofertilizante e da cobertura morta do solo, em ambas as lâminas de irrigação testada. Verificase, na lâmina de $50 \%$ da ETc, que o maior acúmulo de óleo foi obtido sem a utilização da cobertura morta quando as plantas foram adubadas com 2,19 $\mathrm{L}_{\text {planta }}{ }^{-1}$ de biofertilizante correspondente ao teor de 40,46\% de óleo vegetal; no entanto, o cultivo sob condições de cobertura morta obteve respostas decrescentes em relação à aplicação do biofertilizante, o que pode estar relacionado ao fato de que a cobertura morta acelerou o processo de decomposição do biofertilizante no solo em virtude da maior umidade do mesmo; todavia, esta não foi suficiente para promover a solubilização dos sais e pode ter acarretado um distúrbio nutricional na planta (Figura 4D) fato este não verificado sob as condições impostas pela lâmina de $100 \%$ da ETc obtendo-se respostas positivas da adubação com biofertilizante sob as duas condições de cobertura do solo verificando-se que as plantas obtiveram, quando cultivadas com cobertura morta, maior acúmulo de óleo nas sementes de $51,06 \%$ quando adubadas com (2,61 L planta ${ }^{-1}$ ) (Figura 4A), resultados superiores aos obtidos por Severino et al. (2006), Silva et al. (2007) e Nobre et al. (2012), nas cultivares BRS Nordestina e BRS Energia, respectivamente (49\% de óleo) fato que pode estar relacionado à maior disponibilidade hídrica $\mathrm{e}$ de nutrientes às plantas de mamoneira.

\section{Conclusões}

1. A adubação com 3,6 L de biofertilizante promove, associada à cobertura morta e irrigações correspondentes $100 \%$ da ETc, o maior crescimento e produção da mamoneira BRS-188 Paraguaçu

2. O uso da cobertura morta associada ao nível de biofertilizante 3,6 L com irrigações correspondentes 50\% da
ETc, proporciona crescimento e produção semelhantes às plantas cultivadas em sistema convencional, sem cobertura e irrigadas com $100 \%$ da ETc.

\section{Literatura Citada}

Araújo, D. L.; Chaves, L. H. G.; Mesquita, E. F.; França, C. P. Crescimento da mamoneira cultivar BRS-149 Nordestina adubada com nitrogênio, fosforo e potássio. Engenharia Ambiental: Pesquisa e Tecnologia, v.6, p.685-702, 2009.

Dantas, G. F.; Melo, D. S.; Maia Filho, F. C. Barbosa, M. A.; Mesquita, E. F.; Andrade, R. Características biométricas da mamoneira EBDA MPB1, adubada com biofertilizante bovino. Cadernos de Agroecologia, v.6, p.1-5, 2011.

Diniz Neto, M. A.; Távora, F. J. A. F.; Crisóstomo, L. A.; Diniz, B. L. M. T. Adubação NPK e épocas de plantio para mamoneira. II Componentes das fases vegetativas e reprodutivas. Revista Ciência Agronômica, v.40, p.417-426, 2009.

Ferreira, D. F. Sisvar: A computerstatisticalanalysis system. Ciência e Agrotecnologia, v.35, p.1039-1042, 2011.

Formiga, L. A. influência da água disponível do solo em dois cultivares de mamona, nos primeiro e segundo ciclos de produção. Campina Grande: UFCG, 2011. 143p. Tese Doutorado

EMBRAPA - Empresa Brasileira de Pesquisa agropecuária. Centro Nacional de Pesquisa de Solos. Sistema Brasileiro de Classificação de Solos. 3. ed. Brasília: Embrapa Solos, 2013. 353p.

Freitas, C. A. S.; Bezerra, F. M. L.; Silva, A. R. A.; Pereira Filho, J. V.; Feitosa, D. R. C. Comportamento de cultivares de mamona em níveis de irrigação por gotejamento em Pentecoste, CE. Revista Brasileira de Engenharia Agrícola e Ambiental, v.14, p.1059-1066, 2010. http://dx.doi.org/10.1590/S1415-43662010001000006

Larcher, W. Ecofisiologia vegetal. São Carlos: RIMA Artes e Textos, 2006. 532p.

Marenco-Centeno, C. R.; Azevedo, C. A. V.; Santos, D. B.; Lira, V. M.; Santos, J. B. Estimación de la evapotranspiración del ricino (Ricinus communis L.) cv. BRS Energía regado con diferentes niveles de agua salina. Agrociencia, v.46, p.321-331, 2012.

Menezes, R. S. C.; Oliveira, T. S. Mudanças na fertilidade de um Neossolo Regolítico após seis anos de adubação orgânica. Revista Brasileira de Engenharia Agrícola e Ambiental, v.12, p.251-257, 2008. http://dx.doi.org/10.1590/S1415-43662008000300005

Mesquita, E. F.; Chaves, L. H. G.; Guerra, H. O. C.; Lacerda, R. D. Crescimento e produção de duas cultivares de mamoneira sob fertilização NPK. Revista Caatinga, v.25, p.35-43, 2012.

Nascimento, R. C. O uso do biofertilizante em solos agrícolas do cerrado da região do alto Paranaíba (MG). Boletim Goiano Geografia, v.30, p.55-66, 2010.

Nobre, R. G.; Lima, G. S.; Gheyi, H, R.; Medeiros, E. P.; Soares, L. A. A.; Alves, A. N. Teor de óleo e produtividade da mamoneira de acordo com a adubação nitrogenada e irrigação com água salina. Pesquisa Agropecuária Brasileira, v.47, p.991-999, 2012. http:// dx.doi.org/10.1590/S0100-204X2012000700016

Ribeiro, M. C. F.; Rocha, F. A.; Santos, A. C.; Silva, J. O.; Peixoto, M. F. S. P.; Paz, V. P. S. Crescimento e produtividade da mamoneira irrigada com diferentes diluições de esgoto doméstico tratado. Revista Brasileira Engenharia Agrícola e Ambiental, v.16, p.639646, 2012. http://dx.doi.org/10.1590/S1415-43662012000600008 
Severino, L. S.; Ferreira, G. B.; Moraes, C. R. A.; Gondim, T. M. S.; Freire, W. S. A.; Castro, D. A.; Cardoso, G. D.; Beltrão, N. E. M. Crescimento e produtividade da mamoneira adubada com macronutrientes e micronutrientes. Pesquisa Agropecuária Brasileira, v.41, p.563568, 2006. http://dx.doi.org/10.1590/S0100-204X2006000400003

Silva, S. F.; Araújo, D, L.; Freitas, B. V.; Araújo, D. L.; Mesquita, E. F. Comportamento fisiológico do milho sob manejo orgânico. Revista Verde de Agroecologia e Desenvolvimento Sustentável, v.6, p.33-39, 2011.

Silva, S. M. S.; Alves, A. N.; Gheyi, H. R.; Beltrão, N. E. De M.; Severino, L. S.; Soares, F. A. L. Desenvolvimento e produção de duas cultivares de mamoneira sob estresse salino. Revista Brasileira de Engenharia Agrícola e Ambiental, v.12, p.335-342, 2008. http://dx.doi.org/10.1590/S1415-43662008000400001

Silva, T. R. B.; Leite, V. E.; Silva, A. R. B.; Viana, L. H. Adubação nitrogenada em cobertura na cultura da mamona em plantio direto. Pesquisa Agropecuária Brasileira, v.42, p.1357-1359, 2007. http://dx.doi.org/10.1590/S0100-204X2007000900018
Sousa, J. A.; Guerra, H. O. C. Crescimento inicial do pinhão-manso (Jatropha curcas L.) em função da irrigação, adubação orgânica e cobertura do solo. Revista Caatinga, v.25, p.104-112, 2012.

Souza, E. R.; Montenegro, A. A. A.; Montenegro, S. M. G. L. Variabilidade espacial da umidade do solo em Neossolo Flúvico. Revista Brasileira de Recursos Hídricos, v.13, p.177-187, 2008.

Souza, N. C.; Mota, S. B.; Bezerra, F. M. L.; Aquino, B. F.; Santos, A. B. Produtividade da mamona irrigada com esgoto doméstico tratado. Revista Brasileira Engenharia Agrícola e Ambiental, v.14, p.478-484, 2010. http://dx.doi.org/10.1590/S141543662010000500004

Taiz, L.; Zeiger, E. Fisiologia vegetal. 5.ed. Porto Alegre: Artmed, 2013. 918p.

Wendt, C. W. Use of a relationship between leaf length and leaf área of cotton (Gossypiumhirsuntum L.), castor (Ricinus communis L.) and sorghum (Sorghum vulgare L.). Agronomy Journal, v.59, p.485-487, 1967. http://dx.doi.org/10.2134/agronj1967.0002196 $2005900050034 x$ 